\title{
Modelo operativo de promoción de la salud y prevención de enfermedades bucales en preescolares de Cuautla, Morelos-México
}

\author{
José Francisco Flores-Alatorre ${ }^{1}$, *Cristina Raquel Caballero-García ${ }^{2}$, Pastor Bonilla-Fernández ${ }^{3}$, \\ Rosaura Atrisco-Olivos ${ }^{4}$, María de la Luz Arenas-Monreal ${ }^{5}$ \\ ${ }^{1}$ Universidad Autónoma de Asunción (UAA). Paraguay \\ zinisterio de Salud Pública y Bienestar Social. Paraguay \\ ${ }^{3}$ Universidad Autónoma del Estado de Morelos - Carrera de Enfermería, México \\ ${ }^{4}$ Instituto Nacional de Salud Pública de México / Escuela de Salud Pública de México, México \\ ${ }^{5}$ Instituto Nacional de Salud Pública de México / Centro de Investigaciones en Sistemas de Salud, México
}

Cómo referenciar este artículo/

How to reference this article:
Flores-Alatorre JF, Caballero-García CR, BonillaFernández $\mathbf{P}$, Atrisco-Olivos $\mathbf{R}$, Arenas-Monreal ML. Modelo operativo de promoción de la salud y prevención de enfermedades bucales en preescolares de Cuautla, Morelos-México. Mem. Inst. Investig. Cienc. Salud. 2019; 17(1): 82-92

\section{RES U M E N}

Las estrategias tradicionales para abordar la salud bucal en México han carecido de un enfoque integrado a la promoción de la salud y a los factores de riesgo en común con otras patologías, principalmente crónicas. De unir esfuerzos se aprovecharían mejor los limitados recursos sanitarios. Esta investigación tuvo como objetivo implementar un modelo operativo de promoción de la salud y prevención de las enfermedades bucales, usando un ciclo de mejora continua en el preescolar de la comunidad Peña-Flores, Cuautla, Morelos. Se realizó un estudio cuasi-experimental con 120 niños de ambos sexos. La implementación contempló: diagnóstico epidemiológico bucal y social, capacitación de actores clave, ejecución del programa de salud bucal, monitoreo, análisis y evaluación de resultados. Se levantaron datos mediante una guía de observación participante, de reuniones con madres de familia y maestras bajo la perspectiva participativa del triple diagnóstico de educación popular. Se determinó el índice de dientes cariados, a extraer y obturados. Se realizó la medición de la placa dento-bacteriana utilizando el índice de sedimento dental (DIS). Como resultado del control y sistematización del proceso de cepillado dental y del monitoreo de la placa dento-bacteriana, se identificó una disminución del DIS de 1,04 a 0,47. Con la implementación de un menú escolar, se mejoró la alimentación infantil. El modelo implementado constituye una posible solución a la problemática de salud bucal del preescolar de la comunidad Peña-Flores, situado en un contexto de desventaja social por factores como pobreza, migración y déficit de servicios públicos.

Palabras clave: salud bucodental, promoción de la salud, prevención de enfermedades bucales, mejora continua.

\section{Operational model of health promotion and prevention of oral diseases in preschool children in Cuautla, Morelos- Mexico}

\section{A B S T R A C T}

Traditional strategies to address oral health in Mexico have lacked an integrated approach to the promotion of health and risk factors in common with other pathologies, mainly chronic. Uniting efforts would make better use of limited health resources. The objective of this research was to implement an operational model of health promotion and prevention of oral diseases, using a cycle of continuous improvement in the preschool community of PeñaFlores, Cuautla, Morelos. A quasi-experimental study was conducted with 120 children of both sexes. The implementation included: buccal and social epidemiological diagnosis, 
training of key players, execution of the oral health program, monitoring, analysis and evaluation of results. Data were collected through a participant observation guide, meetings with mothers and teachers under the participatory perspective of the triple diagnosis of popular education. The index of decayed, extracted and filled teeth was determined. The dento-bacterial plaque was measured using the dental sediment index (DIS). As a result of the control and systematization of the dental brushing process and the monitoring of the bacterial plaque, a DIS decrease of 1.04 to 0.47 was identified. With the implementation of a school menu, children's nutrition was improved. The model implemented is a possible solution to the problem of oral health of the preschool of the Peña-Flores community, located in a context of social disadvantage due to factors such as poverty, migration and lack of public services.

Keywords: oral health, health promotion, prevention of oral diseases, continuous improvement.

\section{INTRODUCCIÓN}

Las estrategias tradicionales para abordar la salud bucal en México han carecido de un enfoque integrado a la promoción de la salud y a los factores de riesgo en común con otras patologías, principalmente las enfermedades crónicas ${ }^{(1)}$. Esta problemática es consecuencia de la des-articulación en la planificación estratégica, en los programas, planes, normas, recursos humanos, etc., en todos los niveles de gobierno que, además, incluye limitaciones para evaluar los programas ${ }^{(2-4)}$.

México ha mostrado un rezago en la promoción de la salud odontológica. Esto coloca a los sectores marginados de la población en desventaja al carecer de los servicios y programas, para solventar esta necesidad. De ese modo, la salud bucodental queda a responsabilidad del individuo, que debe recurrir al gasto de bolsillo lo que causa merma en los recursos económicos familiares ${ }^{(3)}$.

Como lo menciona Frenk ${ }^{(1)}$, de pasar algún accidente o contingencia, la población con poca capacidad de pago recurrirá al gasto de bolsillo para atender esta necesidad de atención. Esto elimina la posibilidad de oportunidades de bienestar entre toda la población. Debido a que además de luchar contra la enfermedad se lucha de igual manera contra la pobreza $^{(1,3,5-9)}$.

Los resultados de la Encuesta Nacional de Caries de México 2001 brindaron una aproximación acerca de la salud bucal en diferentes Estados del país. A nivel nacional, existía una prevalencia de caries en dentición temporaria de $65,05 \%$, con índices de dientes cariados, a extraer, obturados (ceo-d) de 2,25, en edades de 6 a 10 años ${ }^{(10)}$.

En el caso particular del Estado de Morelos, la prevalencia de caries reportada fue de $80,26 \%$ y el índice ceo-d de 3,34 en dentición infantil. Ambas cifras muy altas en comparación al nivel nacional ${ }^{(10)}$. Es de resaltar que el mayor componente del índice ceo-d estaba dado por la caries. Lo anterior, mostraba un elevado grado de enfermedad, así como la carencia de atención preventiva y $\operatorname{curativa}^{(4,6,7,11)}$. Esta situación era igual de alarmante en otros Estados del país con prevalencia de caries de $87,15 \%$ y en la Ciudad de México con una prevalencia $82,69 \%{ }^{(10)}$.

Al momento del estudio, la comunidad de Peña-Flores ubicada en Cuautla, Morelos, se encontraba en un estado de transición debido a que tenía características rurales y con tendencia a la urbanización. El trazado urbanista era desordenado, y la carencia de algunos servicios públicos indispensables hacía estragos en la salud de la población. En el centro de la localidad, se encontraba el preescolar Ignacio M. Altamirano, institución que nació por la donación del Ejido del pueblo de Calderón, como respuesta a las necesidades de acceso a la educación de los hijos de trabajadores de la región ${ }^{(12)}$.

La presente investigación abordó el problema de la caries dental, afección que enfrenta importantes retos en la comunidad de Peña-Flores ${ }^{(12)}$ y que son comunes a poblaciones con igual situación social ${ }^{(5-9,13)}$, entre ellos: pocos servicios odontológicos públicos accesibles en las áreas económicamente deprimidas y en zonas las rurales; reducidos programas de educación para la salud dental adecuados; proveedores públicos de salud bucal con paquetes limitados para la atención; elevada necesidad de tratamientos que sólo se logran sufragar en atención privada, sumado a que sólo el $8,53 \%$ de la población era atendida en el sector privado ${ }^{(12)}$.

Partiendo de que las escuelas son un entorno ideal para crear espacios y prácticas saludables ${ }^{(14)}$, así como de los resultados de investigaciones que documentaron disminución 
en el índice de sedimento dentario (DIS), en los sectores más vulnerables con medidas como práctica de cepillado dental asistido y reducción de azucares refinados ${ }^{(9,13,15-17)}$, el objetivo de este estudio fue implementar un Modelo Operativo de Promoción de la Salud y Prevención de Enfermedades Bucales en preescolares, a través del ciclo de mejora continua ${ }^{(18-23)}$.

El modelo propuesto buscó controlar la incidencia de caries en la dentición temporaria (mediano plazo), para disminuir la morbilidad por caries en la dentición permanente (largo plazo) $)^{(9,13,15-17,22,24,25)}$.

Para cumplir con el mencionado objetivo, se abordó el control del pre-evento común de las enfermedades bucodentales que es: la acumulación de placa dento-bacteriana y sus factores de riesgo asociados ${ }^{(13,15,17,24,25)}$ (Figura 1).

\begin{tabular}{|c|c|c|c|}
\hline Factor & Pre-evento & Evento & Post-evento \\
\hline Huésped & $\begin{array}{l}\text {-Saliva con Ph. Ácido } \\
\text {-Dientes con } \\
\text { caracteristicas } \\
\text { anatómicas susceptibles } \\
\text {-Nutrición }\end{array}$ & $\begin{array}{l}\text { Dientes dañados } \\
\text { asintomático }\end{array}$ & $\begin{array}{l}\text { Restauración del Diente } \\
\text { Extracción del Diente } \\
\text { Complicaciones } \\
\text { infecciosas }\end{array}$ \\
\hline Vector & $\begin{array}{l}\text {-Presencia de Placa } \\
\text { dento-bacteriana (PDB) }\end{array}$ & $\begin{array}{l}\text { La PDB se acumula en la } \\
\text { lesión del órgano dentario }\end{array}$ & \\
\hline Agente & $\begin{array}{l}\text {-Tipo de flora bucal } \\
\text {-Momento de inoculación } \\
\text { Productos metabólicos }\end{array}$ & $\begin{array}{l}\text { Bacterias colonizan el } \\
\text { diente alimentándose del } \\
\text { tejido dental reblandecido. }\end{array}$ & $\begin{array}{l}\text { Bacterias ingresan a la } \\
\text { cavidad pulpar } \\
\text { causando molestias } \\
\text { fisicas. }\end{array}$ \\
\hline $\begin{array}{l}\text { Ambiente } \\
\text { social }\end{array}$ & $\begin{array}{l}\text {-Poco hábito de cepillado } \\
\text {-Dieta alta en } \\
\text { carbohidratos } \\
\text {-Dieta con poca auto- } \\
\text { limpieza (autoclisis bucal) }\end{array}$ & $\begin{array}{l}\text { Poco hábito de cepillado y } \\
\text { mayor acumulación en } \\
\text { zonas donde hay } \\
\text { cavidades. } \\
\text { Limitada atención a la } \\
\text { salud, miedo al dentista, } \\
\text { etc. }\end{array}$ & $\begin{array}{l}\text { Proceso de búsqueda de } \\
\text { la atención } \\
\text { Cartera limitada de } \\
\text { servicios y/o insumos } \\
\text { Dificultades del acceso a } \\
\text { los servicios } \\
\text { Atención privada con } \\
\text { altos costos en la } \\
\text { atención. }\end{array}$ \\
\hline & $\begin{array}{l}\text { Área de Trabajo del } \\
\text { Modelo propuesto }\end{array}$ & & \\
\hline
\end{tabular}

Fuente: Leavel H. Clark R. Gurney E. Concepts of prevention to practice social. 2nd edition, McGraw-hill book company. 1958. ${ }^{(26)}$ Adaptado por: Flores-Alatorre JF.

Figura 1. Historia Natural de la Enfermedades Bucales según Levell y Clark

\section{MATERIALES Y MÉTODOS}

Se realizó un estudio cuasi-experimental ${ }^{(27)}$ con mediciones pre y post implementación del modelo operativo durante el periodo de noviembre del 2008 a julio del 2009. La población de estudio fueron 120 niños de ambos sexos (divididos en 5 grupos) inscritos en el preescolar Ignacio M. Altamirano de la comunidad de Peña-Flores ubicada en Cuautla, Morelos. Fueron criterios de exclusión el rechazo de los niños o de los padres para que sus hijos participaran en el estudio.

La variable dependiente fue la placa dento-bacteriana. Las variables independientes fueron el modelo operativo implementado, las variables sociodemográficas, la frecuencia del consumo de alimentos, el índice ceo-d y el cepillado correcto.

Procedimiento

El modelo operativo de promoción de la salud y prevención de enfermedades bucales en preescolares contó con una serie de pasos que permitieron al facilitador obtener información y sistematizarla para su análisis, la obtención de propuestas para la implementación, los datos para la mejora continua y la evaluación (Figura 2 ). 


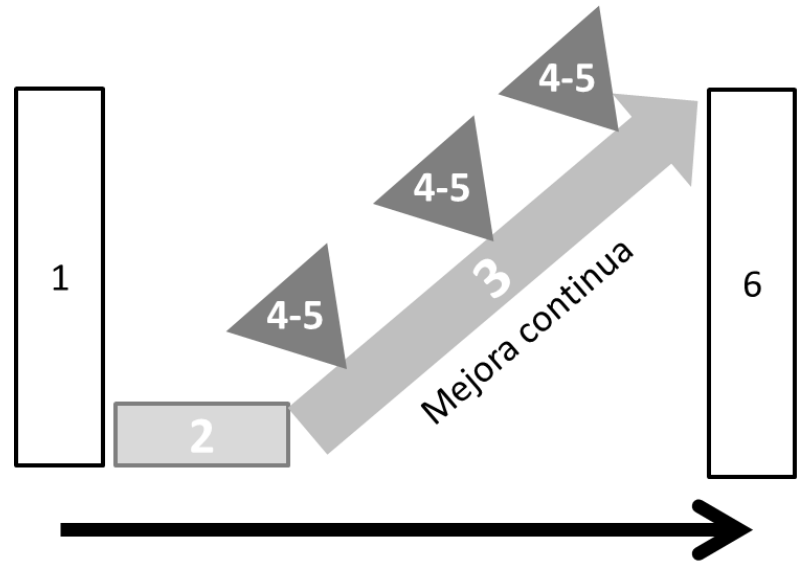

1. Diagnóstico situacional epidemiológico bucal y social en el preescolar

2. Capacitación de actores clave

3. Implementación del programa

4. Monitorización del proceso

5. Verificación de la información

6. Evaluación del impacto a mediano plazo

Fuente: Modelo Operativo de Promoción de la Salud Bucal y Prevención de Enfermedades Bucales en preescolares de Peña-Flores, Cuautla, Morelos-México. 2008-2009.

Figura 2. Esquema de trabajo del Modelo Operativo de Promoción de la Salud y Prevención de Enfermedades Bucales en preescolares.

\section{Diagnóstico situacional epidemiológico bucal y social en el preescolar:}

La información fue recolectada a través de una guía de observación participante con el fin de conocer los usos y costumbres en cuanto a la alimentación y la higiene del preescolar, así como, tener un acercamiento real con la comunidad. Se complementaron con información recolectada en reuniones con madres de familia y maestras bajo la perspectiva participativa usando el triple diagnóstico de educación popular ${ }^{(28,29)}$. (Figura 2)

Los datos cuantitativos se recolectaron, previo consentimiento informado de los padres, a través del índice ceo-d $\mathrm{d}^{(9-11,13,16,24,30-32)}$. Posteriormente se realizó la medición de la placa dento-bacteriana mediante el DIS, que forma parte del índice de higiene oral simplificado (IHOS), creado por Green y Vermillion en $1964^{(30)}$. Con la diferencia del uso de la tableta reveladora que permitió obtener un resultado más preciso en la medición ${ }^{(31)}$.

2. Capacitación de actores clave

Se entregó a las maestras un informe sobre la situación dental de los niños y se socializó sobre los datos recolectados en la etapa diagnóstica del proyecto $(28,29,33)$. Para entender y analizar la problemática de la comunidad, se utilizó el árbol de problemas y el árbol de objetivos, lo que permitió al investigador, diseñar estrategias acordes a las necesidades del contexto ${ }^{(18,20,33,34)}$. (Figura 2)

Las estrategias diseñadas fueron: Estrategia 1: Romper el círculo vicioso de falta de importancia de salud bucal; Estrategia 2: Mejorar las condiciones de alimentación dentro de la escuela y; Estrategia 3: Mejorar los hábitos de higiene oral.

3. Implementación del programa:

Se realizó una implementación de las estrategias siguiendo una programación establecida bajo la perspectiva de mejora continua(18-20). (Figura 2)

Estrategia 1: Romper el círculo vicioso de falta de importancia de salud bucal, con acciones de impacto social sugeridas y seleccionadas por las maestras de acuerdo al desarrollo de habilidades establecidas en su programa de educación y con el objetivo principal de motivar la participación de los padres de familia a través de los niños.

Se dividió en 2 componentes:

A. Actividades escolares para niños: Plática de abordaje de acercamiento con los niños del pre-escolar; elaboración de taller de boca, taller de nutrición infantil e iluminación de juego de memoria grupal.

B. Actividades para la comunidad escolar en general (niños, maestras y padres de familia): Elaboración de un periódico mural; elaboración de taller de cepillado para padres de familia, maestras y alumnos.

Estrategia 2: Mejorar las condiciones de alimentación dentro de la escuela a través de talleres de alimentación diferenciadas para niños, padres y maestros. Se concluyeron los talleres con la elaboración de un menú semanal (para nueve semanas) para los preescolares, utilizando guías de alimentación ${ }^{(35,36)}$ y cuidando que los insumos básicos para la preparación de los alimentos se encontraran disponibles en el mercado local. La 
implementación del menú se inició en la segunda semana con el inicio de la práctica de cepillado.

Estrategia 3: Mejorar los hábitos de higiene oral con la práctica de cepillado como una actividad constante, sistematizada y estandarizada en la escuela con la ayuda de las maestras. En esta actividad se estandarizaron los materiales a usar, principalmente el cepillo dental, cepillero y el vaso ${ }^{(18,20)}$. Se cuidó de revisar y asegurar que la higiene dental sea efectiva, con la monitorización del proceso a través del índice de sedimento dental ${ }^{(24,25,30-32)}$.

Con la implementación de las estrategias se fortaleció el canal de comunicación entre maestras y madres/padres de familia. Con pizarrones coloridos de material de fomi ${ }^{\circledR}$ (goma eva), colocados a un lado de la puerta del salón, esto con el fin de tener un lugar de comunicación para tareas y principalmente para la difusión del menú semanal y de los resultados de las evaluaciones de la placa dento-bacteriana.

4. Monitorización del proceso:

Se realizó una planilla de evaluación de procesos para evaluar las actividades del cepillado y la efectividad del mismo. Con la planilla se verificaba los componentes de la estructura, el proceso y el resultado de los procesos, mediante muestreos a conveniencia de la población participante. (Figura 2)

Estructura: Cepillero adecuado; cepillos adecuados; vasos para el cepillado y agua potable.

Proceso: Cepillos adecuados y vasos adecuados al momento de la ejecución de la práctica, tiempo de práctica de cepillado y el DIS, realizado en 15 niños seleccionados al azar (18-23, 30${ }^{32)}$, como monitorización de la eficacia después de cada práctica de cepillado ${ }^{(18-23,30-32,34)}$.

Resultado del proceso: EI DIS y la recolección de datos sobre los refrigerios consumidos por los escolares ${ }^{(18-23,35,36)}$. (Figura 2)

5. Verificación de la información:

Una vez finalizada la actividad se cotejaba con las maestras los resultados de la medición de placa dento-bacteriana y al terminar la semana se les entregaba un resultado graficado. También se les mostraba y comentaba los datos de otros indicadores de proceso para la mejora de la implementación. Los resultados se pegaban en los pizarrones para que fueran visualizados por madres/padres de familia ${ }^{(34)}$. De esta manera se daba a conocer a la comunidad los avances en materia de higiene bucodental ${ }^{(18-23,30-32,34,)}$. (Figura 2)

6. Evaluación del impacto a mediano plazo:

Se realizó una comparación pre-post ${ }^{(27)}$ implementación del modelo operativo de los indicadores de estructura, proceso y resultados ${ }^{(18-23,34)}$ (Figura 2)

Análisis del estudio

Los datos cuantitativos fueron analizados utilizando el paquete estadístico Stata versión 9. Las pruebas estadísticas se realizaron con un nivel de confiabilidad estadística del 95\%.

Aspectos éticos

El estudio fue aprobado por el comité de ética del Instituto Nacional de Salud Pública de México. A las madres/padres de familia y a los profesores se les dio una carta solicitando su consentimiento. A los niños se les leyó una carta de asentimiento y se pidió su consentimiento de forma verbal y escrito.

\section{RESULTADOS}

La prevalencia de caries en la población estudiada fue del $83 \%$. El índice ceo-d fue de 4,66 y sus componentes fueron 4,4 caries, 0,02 dientes con indicación a extracción y 0,18 dientes obturados.

\section{Indicadores de estructura}

El cepillero con características adecuadas al contexto fue de un $20 \%$ y se mantuvo en ese nivel, debido a que no se pudo implementar ninguna de las ideas sugeridas por la dificultad de cumplimiento con los criterios del mismo. En cuanto a cepillo dental y vaso adecuados, hubo incrementos al comparar las mediciones pre y post implementación del programa (Figura 3). 


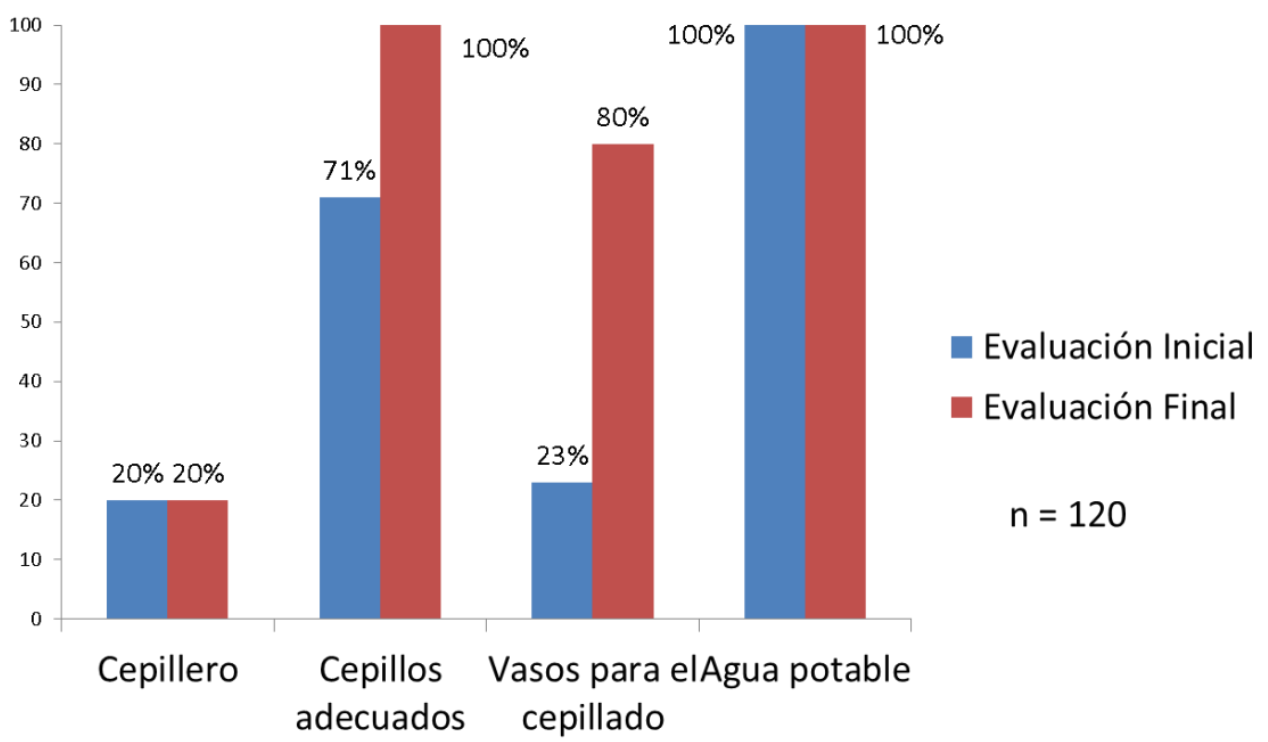

Fuente: Modelo Operativo de Promoción de la Salud Bucal y Prevención de Enfermedades Bucales en preescolares de Peña-Flores, Cuautla, Morelos-México. 2008-2009.

Figura 3. Indicadores de estructura para la práctica de cepillado dental.

\section{Indicadores de proceso}

El tiempo en el que se realizó el cepillado dental fue un indicador de cómo fue hecha la actividad. Los resultados de la figura 4 indican que hubo una disminución en los tiempos de la primera a la segunda semana. De un tiempo promedio de 44 minutos (en los 5 grupos) pasó a 23 minutos por práctica en la segunda semana. En la tercera semana hubo un aumento de 3 minutos. (Ver Figura 4)

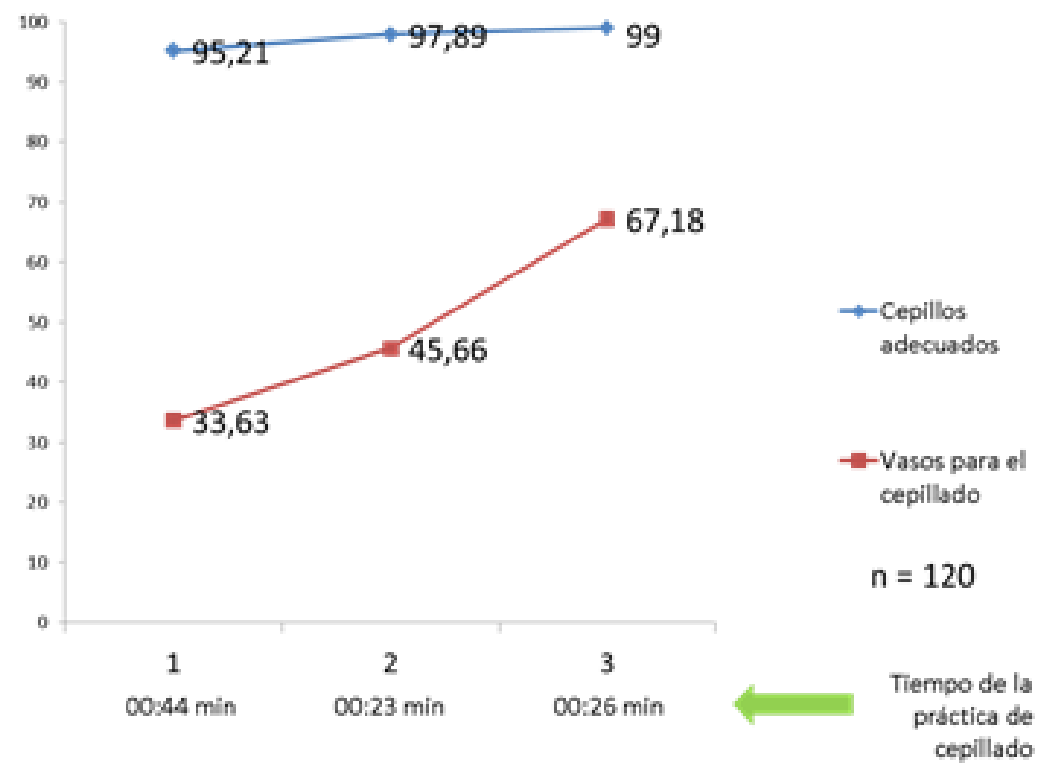

Fuente: Modelo Operativo de Promoción de la Salud Bucal y Prevención de Enfermedades Bucales en preescolares de Peña-Flores, Cuautla, Morelos-México. 2008-2009.

Figura 4. Indicadores de proceso de la práctica de cepillado dental.

En cuanto a los insumos básicos para la práctica de cepillado (cepillo y vaso), en la primera semana de implementación se alcanzó el 95,21\% de cobertura en cepillos dentales, en la segunda semana un $97,89 \%$ y en la tercera semana un $99 \%$ (Figura 4). En cuanto al indicador de vasos para la práctica, en la primera semana se alcanzó un $33,63 \%$, en la segunda semana un $45,66 \%$ y en la tercera semana un $67,18 \%$ (Figura 4 ).

EI DIS/ indicador de PDB como indicador de proceso de la práctica de cepillado, fue disminuyendo de 1,3 en la primera semana a 0,97 en la segunda semana y, finalmente a 0,77 en la última medición (Figura 5 / línea continua - control del proceso). 


\section{Indicadores de resultados}

Los principales indicadores de resultado fueron: La disminución de la placa dentobacteriana, como mecanismo de evaluación de la intervención, disminuyó de 1,04 a 0,47 según la medición del DIS, indicando una disminución estadísticamente significativa del 45,86\% (Figura 5 / barras del histograma - pre-pos intervención).

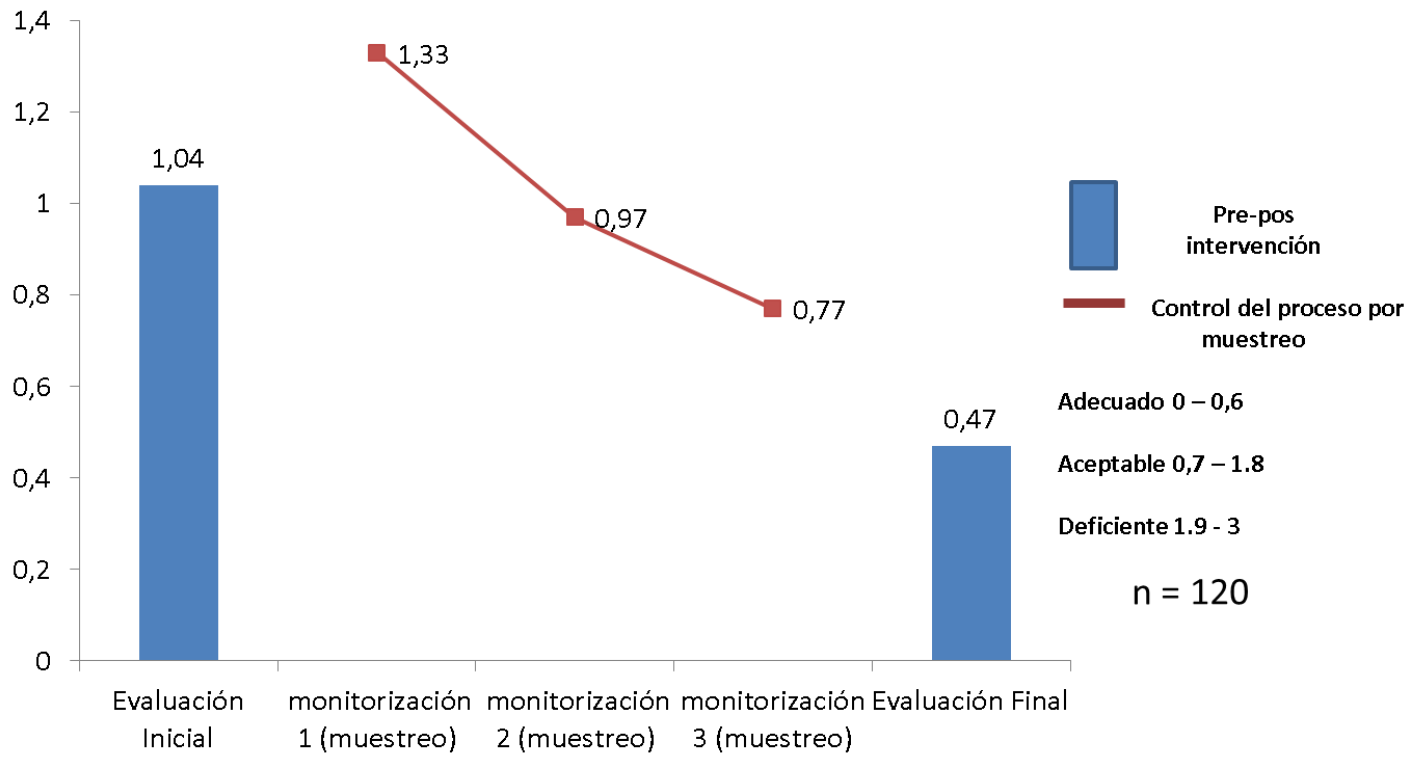

Fuente: Modelo Operativo de Promoción de la Salud Bucal y Prevención de Enfermedades Bucales en preescolares de Peña-Flores, Cuautla, Morelos-México. 2008-2009.

Figura 5. Indicadores de resultado-Índice de Sedimento Dental (DIS) como pre-post implementación del programa y como indicador de proceso de la práctica de cepillado.

Se logró mejorar la alimentación infantil dentro de la escuela, con la implementación de un menú semanal. Se aumentó el consumo de alimentos elaborados manualmente en casa con productos naturales (AEMCMPN), pasando del $21 \%$ al $51 \%$ (Figura 6 ).

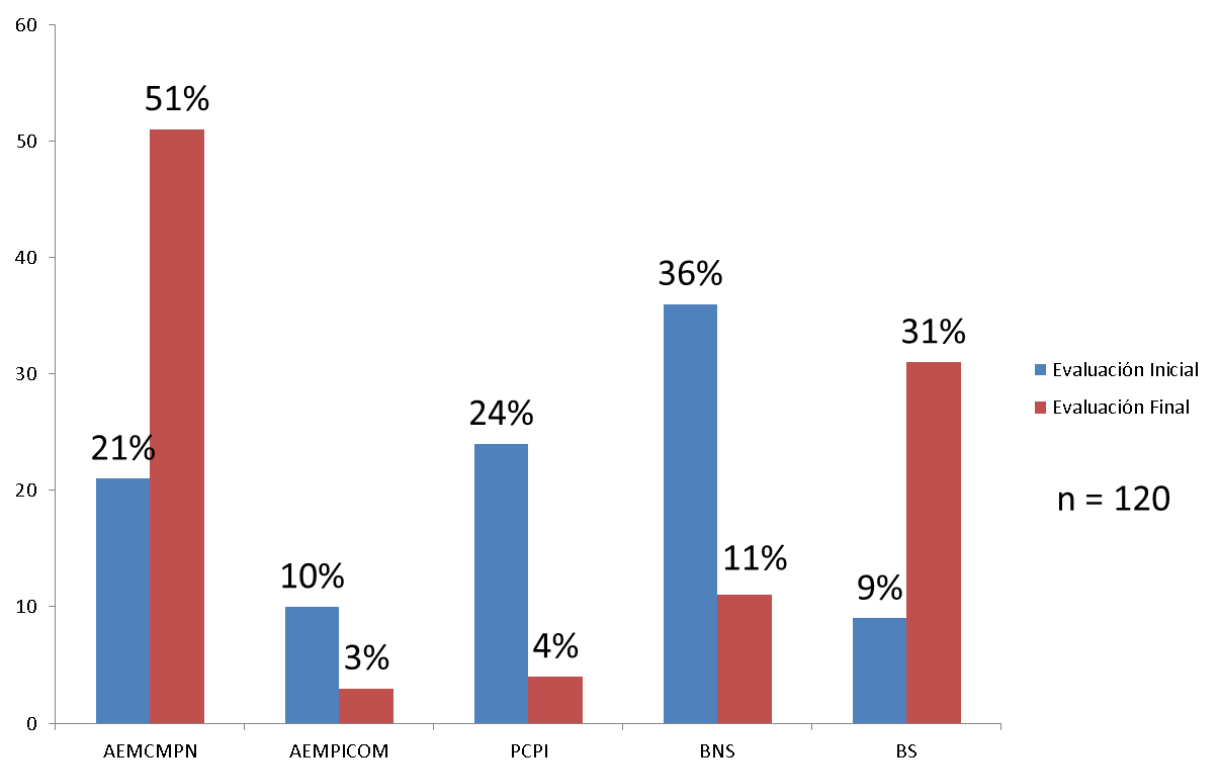

*AEMCMPN: Alimentos elaborados en manualmente casa con productos naturales; AEMCOM: Alimentos elaborados manualmente con productos industriales comprados; PC: Productos comerciales de preparación industrial; BNS: Bebidas no saludables; BS: Bebidas Saludables

Fuente: Modelo Operativo de Promoción de la Salud Bucal y Prevención de Enfermedades Bucales en preescolares de Peña-Flores, Cuautla, Morelos-México. 2008-2009.

Figura 6. Indicadores del resultado-Patrón de consumo de alimentos dentro del preescolar. 
Los alimentos elaborados manualmente con productos industriales comprados (AEMPICOM), para el consumo en el recreo, tuvieron una disminución del $10 \%$ al $3 \%$. El alimento que más se compraba afuera de la escuela era el sándwich o emparedado, que lo elaboraba la señora que vendía dulces. Debido a la implementación del programa, el consumo de emparedado se cambió por el consumo de fruta, que lo elaboraba la señora de los jugos y licuados (Figura 6).

Los productos comerciales de preparación industrial (PCPI) disminuyeron sustancialmente por el efecto del menú semanal del $24 \%$ al inicio al $4 \%$ posterior a la implementación del programa. Se observó el mismo efecto con el consumo de bebidas no saludables (BNS) que del $36 \%$ disminuyó al $11 \%$ al final del proyecto. También se evidenció un cambio positivo con relación a las bebidas saludables (BS) que aumentaron del 9\% al 31\% (Figura 6).

\section{Resultados de las reuniones con actores clave}

Padres de familia

Los padres de familia refirieron una mejora en los conocimientos sobre higiene dental, considerando importante y novedosa la información de los talleres. También refirieron que la información fue suficiente y que les interesaría hablar más acerca del flúor.

Les agradó la convivencia con los niños en una práctica de salud, que les generó el interés a los niños hacia el cepillado dental y a los padres de cómo enseñarles a cepillarse. También fue de su gusto que el proyecto ayudó a los niños a no tener miedo de ir al dentista. Refirieron que el menú les ayudó a que coman menos alimentos dañinos como los dulces.

Consideraron que vale la pena este tipo de proyectos porque: "-Se gana salud y menos dolores de muela" (Testimonio de un abuelo responsable de un niño participante del preescolar).

Maestras

Relataron mejora en los conocimientos acerca de los cuidados de higiene y cepillado dental. Se consideró la información de los talleres como novedosa por su contenido y alarmante porque los alumnos se encontraban en un riesgo de salud importante.

Les agradó la participación de los padres de familia en los talleres, también la implementación del menú semanal y que los niños mostraron actitud positiva hacia el cepillado dental.

Por otra parte, no les agradó participar en la revisión del cepillado dental, vieron la actividad como un contra-tiempo. Puntualizaron que es importante que exista personal de planta encargado de la higiene bucal de los preescolares en las escuelas. Refirieron la necesidad de mejorar el cepillero dental en los salones, debido a que los actuales no tienen las mejores condiciones de higiene, así también, la provisión de insumos para la higiene del próximo ciclo escolar.

También manifestaron que con estos proyectos los niños pierden el miedo al dentista o a que les revisen su boca. Puntualizando de igual manera que la prevención reduce los gastos de la familia. Se consideró que el menú semanal fue una implementación exitosa ya que ayuda a mejorar la salud de los niños y las familias gastan menos que comprando productos industrializados en la tienda.

\section{DISCUSIÓN}

La problemática de la salud bucal es por demás compleja y aún más en poblaciones con desventajas sociales. Factores como el estrés, carencia de recursos, conflictos familiares, hacen que la salud bucal sea menos accesible para los niños ${ }^{(2-4,5-7,9,13,15-17)}$. Diferentes autores han documentado que los factores mencionados favorecen la aparición de enfermedades con un gran componente social y baja respuesta del Estado para solventar esta brecha de desigualdad ${ }^{(4-8,9,13-17)}$.

La atención preventiva de la salud bucal de las poblaciones con desventaja tiene un gran potencial positivo, que contribuye al bienestar de toda la familia. La detección oportuna y tratamientos preventivos en dentición primaria en áreas de alta marginación, evitan acciones traumáticas que en el futuro serán actitudes no favorables hacia la atención bucodental. Así como infecciones, dolor, mal posición de dientes (maloclusión), entre otros $^{(9)}$.

Es de resaltar que el índice de ceo-d de 4,66 de la población de estudio se encontraba por encima de los datos de la Encuesta Nacional de Salud Bucal ${ }^{(10)}$, donde el promedio era 
de 2,25 en edades de 6 a 10 años ${ }^{(10)}$. Esto quiere decir que la población del preescolar superaba la problemática en salud bucal nacional y en edades más tempranas.

Considerando lo antes expuesto, el modelo operativo de promoción de la salud y prevención de enfermedades bucales en preescolares es una de las posibles soluciones a la problemática de salud bucal de la comunidad Peña-Flores (Palo-verde), perteneciente al municipio de Cuautla. Localidad semi-urbana con un contexto de desventaja social amplia por diferentes factores como pobreza, migración y déficit de servicios públicos.

El modelo operativo propuesto e implementado considera las recomendaciones realizadas por Watt $^{(22)}$ y otros autores ${ }^{(6,7,9,12-17,23,24,25)}$ para el diseño de intervenciones comunitarias desde la perspectiva de la promoción de la salud con un enfoque de mejora continua. Si bien, la resolución de la problemática de la salud bucal es compleja a nivel poblacional, el modelo asegura como mínimo que el ambiente educativo sea un lugar para potencializar la salud oral en preescolares $(1,9,13,15-17,24,25)$.

Diversos autores ${ }^{(3,8-10,13,15,24,25)}$, mencionan la importancia en la disminución de la placa dento-bacteriana para evitar la proliferación de la caries, por lo que disminución del índice de sedimento dental de 1,04 a 0,47, con una disminución significativa en parámetros de Lynde $^{(32)}$, se considera un resultado alentador. Al igual que lo reportado por Battellino ${ }^{(13)}$, la implementación del modelo operativo también mostró una disminución del mencionado índice con estrategias como prácticas de cepillado dental asistida y reducción de azúcares refinados.

Se identificó mejoría en la alimentación infantil dentro de la escuela. Debido a que la alimentación representa una variable fundamental e indispensable para el mejoramiento de la salud general y bucal, la implementación de un menú semanal para nueve semanas contribuyó a que en la segunda medición, hubiese una disminución positiva de la placa dento-bacteriana $(8,13,15,24,25)$.

Otro elemento favorable, fue el aumento del consumo de agua natural y/o bebidas saludables, ya que el preescolar contaba con un alto consumo de bebidas azucaradas $^{(9,13,15,16,35,36)}$.

El control y sistematización del proceso de cepillado dental, así como la monitorización del índice del sedimento dental como método de control de la efectividad del cepillado, representa un avance que permite entender que el pre-evento a caries es controlable bajo la perspectiva de calidad, promoción de la salud y prevención de enfermedades.

Los resultados positivos proporcionados por la intervención y del aprendizaje obtenido en el preescolar se deben al compromiso profesional y la apertura de la comunidad escolar. Esta participación logró que los agentes clave (preescolares, maestros y padres) desarrollaran habilidades para el control de la higiene bucal.

Dentro de las recomendaciones del presente estudio se señalan los siguientes: 1) Seguir con las acciones efectuadas para dar continuidad al trabajo realizado en Peña-Flores, Cuautla - Morelos, consolidando los proyectos iniciados en la promoción de la salud evitando dejar abandonadas a las comunidades ya trabajadas; 2) Mejorar los insumos para la higiene dental como un cepillero dental verdaderamente higiénico, que fue una de las principales controversias en el preescolar; 3) Plantear el mismo estudio en dos poblaciones (caso y control), y preferentemente realizar la investigación de manera completa con el fin de obtener diagnósticos situacionales de poblaciones vulnerables; 4) Continuar con la implementación del cepillado dental como parte de las actividades del preescolar, además del menú semanal; 5) A los colegas odontólogos a participar en actividades de campo a nivel poblacional, y cambiar el paradigma de atención individualizada; 6) Integrar líneas de investigación en salud bucal a nivel poblacional.

\section{AGRADECIMIENTOS}

A la Lic. Patricia Y. Victoria Zárate, Directora del Pre-escolar Ignacio M. Altamirano de la comunidad Peña-Flores, Cuautla - Morelos. Y a su equipo de trabajo: Las profesoras Teresa, Margarita, Francisca, Diana y Mónica, por su ejemplo en la labor de la enseñanza con cariño a los niños de México. Muchas gracias de todo corazón.

Al Consejo Nacional de Ciencia y Tecnología de México (CONACyT - México), por la beca otorgada para mis estudios de posgrado en la Maestría en Salud Pública con énfasis en Administración en Salud, en el Instituto Nacional de Salud Pública de México / Escuela de Salud Pública de México (INSP/ESPM), para la elaboración de esta investigación como trabajo de grado. 


\section{REFERENCIAS BIBLIOGRAFICAS}

1. Frenk Julio. Tender puentes: lecciones globales desde México sobre políticas de salud basadas en evidencias. Salud pública Méx [revista en la Internet]. 2007 Ene [citado 2019 Abr 04] ; 49( Suppl 1 ): s14-s22. Disponible en: http://www.scielo.org.mx/scielo.php?scrip $\mathrm{t}=\mathrm{sci}$ arttext\&pid $=\mathrm{S0036}$ -

$36342007000700006 \&$ Ing $=$ es

2. Lalonde M. A new perspective on the health of the Canadians: a working document. 1ra Ed. Ottawa. Canadá Ottawa: Government of Canada / ;inister of National Healtn and Welfare. 1974. Disponible en: http://www.phacaspc.gc.ca/ph-sp/pdf/perspect-eng.pdf

3. Rivas J, et al. Diagnósticos situacionales en niños de edad preescolar, del Centro de Cuidado Infantil (CECICUAZ), Rev. ADM 2002; LIX 5:161-165. México. DF. Disponible

en: http://www.imbiomed.com/1/1/articulos.p $\mathrm{hp}$ ?method $=$ showDetail\&id_articulo $=3430$ \&id_seccion $=144 \&$ id_ejemplar=395\&id_re vista $=24$

4. Dever A. Epidemiología y administración de servicios de salud. Washington DC. Editorial OPS-Paltex. 1991.

5. Abadía C. Los sistemas de seguridad y atención en América Latina y los efectos en el ejercicio de la odontología: inequidad e injusticia, ética y odontología, una introducción. Acta Bioethica 2006; 12 (1):8-22. ISSN 0717 - 5906.

6. Hobdell M. Poverty oral health and human development: contemporary issues affecting the provision of primary oral health care. J Am Dent Assoc 2007; 138. DOI:

https://doi.org/10.14219/jada.archive. 200 7.0076 Disponible

en: https://jada.ada.org/article/S00028177(14)63773-9/fulltext

7. De la Fuente J, Acosta E. The effect of poverty on access to oral health care. J Am Dent Assoc 2007; 138:1443-1445.

8. Torres S. História social da cárie dentária. EDUSC 2001:124

DOI. https://doi.org/10.14219/jada.archive. 200 7.0078 Disponible

en: https://jada.ada.org/article/S00028177(14)63775-2/fulltext

9. Rayner J, Holt R, Blinkhorn F, Duncan K. BSPD: a policy document on oral health care in preschool children. International Journal of Paediatric Dentistry 2003; 13: 279-285.

DOI: https://doi.org/10.1046/j.1365263X.2003.00463.x

10. CENAVECE. Encuesta Nacional de Salud Bucal 2001. Centro Nacional de Vigilancia Epidemiológica/Secretaria de Salud México. México DF. 2006. ISNB: 970721-396-5. Disponible en: http://www.cenaprece.salud.gob.mx/prog ramas/interior/saludbucal/descargas/pdf/e ncd2001.pdf

11. Chaves M, Frankel J. Utilización de un método sencillo de encuestas para la evaluación de la frecuencia de caries dental en 3009 niños brasileños. Boletín de la Oficina Sanitaria Panamericana 1956; 383-399. Washington DC. EEUU.

12. Flores J, García D, Lara L, González K, Olvera M, Álamo U. Diagnóstico integral de Salud de la localidad de Peña Flores, Cuautla, Morelos 2008. 13vo Congreso de investigación en salud pública (libro de resúmenes) 2008. 57-58 1ra Edición. Instituto Nacional de Salud Pública de México. Cuernavaca. Morelos. México. 2009. ISBN: 978-607-7530-18-3.

13. Battellino L. Evaluación del estado de salud bucodental en preescolares: estudio epidemiológico longitudinal (1993-1994) Córdoba, Argentina. Rev. Saúde Pública 1997; 31: 3: 272-81. Sao Paulo. Brasil. 1997.

14. Caballero CR, Flores JF, Bonilla P, Arenas L. Experiencias de promoción de la salud en escuelas de nivel primario en México. Mem. Inst. Investig. Cienc. Salud. 2017; 15(1): 22-32. Disponible en: http://revistascientificas.una.py/index.php /RIIC/article/view/1163

15. Bordoni, N, coordinador. PRECONC, Odontología preventiva. 1:19. Washington DC. EEUU. OPS-Paltex 1993.

16. Morello P. Servicios de salud escolares en la región de las Américas. Washington, DC. EEUU. División de Desarrollo de Sistemas y Servicios de Salud. OMS/OPS 2003.

17. Dickson M. Where there is no dentist. Eleventh printing, Palo Alto, CA: Hesperian Foundation 2006.

18. Ishikawa K. What is total quality control, the Japanese way. EEUU. Prentice-hall INC, 1985. ISBN-10: 0139524339.

19. Deming WE. Out of the crisis. Massachusetts Institute of Technology, Center for advanced engineering study, Cambridge - MA. EEUU. 1986. ISBN-10: 0262535947.

20. Sandholm L. Control total de la calidad. México DF. Ed Trillas. 1995. ISBN 10: 968245185X.

21. Ovretveit J. Quality in health promotion, Health Promotion International, Volume 11, Issue 1, March 1996, Pages 55-62, https://doi.org/10.1093/heapro/11.1.55

22. Watt RG, et al. Evaluating oral promotion: need for quality outcome measures. Community Dent Oral Epidemiol 2006; 34:11-17. DOI: 10.1111/j.16000528.2006.00257.x. Disponible en: https://www.ncbi.nlm.nih.gov/pubmed/16 423026 . 
23. Kahan B, Goodstadt M. Continuous quality improvement and health promotion: can CQI lead to better outcomes? Health promotion international, Oxford University Press 1999; 14: 1: 83-91. DOI: https://doi.org/10.1093/heapro/14.1.83. Disponible en: https://academic.oup.com/heapro/article/ $14 / 1 / 83 / 624141$

24. Doño R. PRECONC, Odontología Preventiva Control mecánico de placa bacteriana, Medidas preventivas. Washington DC. EEUU. OPS-Paltex 1993; 2:47-74.

25. Grant M. Handbook of community health, Dental Health. Philadelphia EEUU. Lea \& Febinger 1975; 8: 145-171.

26. Leavell H, Clark R, Gurney E. Concepts of prevention to practice social. 2nd edition, New York. EEUU. Mc Graw-hill book company 1958.

27. Gómez G. Piscología de la comunidad, 3ra reimpresión. México DF. Editorial Plaza y Valdés 2008. SBN: 978-84-15271-17-8.

28. Nuñez C. Educar para transformar, transformar para educar. 9ed. Guadalajara. Jalisco. México. IMDEC. 1992.

29. Arenas Monreal Luz, Paulo Maya A. López González H. Educación popular y nutrición infantil: Una experiencia de trabajo con mujeres en una zona rural de México. Rev Saúde Pública. vol33, no.2, 1999:113-12.

30. Green J, Vermillion J. Oral higiene index: a method for classifying oral higiene status. J Am Dent Assoc 1964; 68:7-13.

31. Saliba N, Tumang A, Saliba O. Estudio comparado del índice de higiene oral simplificado. Boletín de la oficina sanitaria panamericana $1974 ; 115-121$.

32. Lindhe J. Periodontología Clínica. México DF. Edit. Médica Panamericana 1992; pp2:73.

33. Vargas $L$, Bustillos G. Técnicas participativas de educación popular. 2da ed. San José de Costa Rica. Editorial Centro de Estudios y Publicaciones Alforja, 1998. ISBN: 9977-926-00. Disponible en: https://docenteslibresmdq. files.wordpress. com/2014/04/cide-tecnicas-participativaspara-la-educacion-popular-ilustradas.pdf

34. Martínez J. Guía práctica para mejorar la atención del paciente con tuberculosis, Un enfoque participativo. México DF. OMSOPS 2008. Disponible en: https://www.paho.org/mex/index.php?opt ion=com_docman\&view =document\&layou $\mathrm{t}=$ default\&alias $=26$-guia-practica-paramejorar-la-atencion-del-paciente-contuberculosis-un-enfoqueparticipativo\&category_slug=ops-omsmexico\&Itemid $=493$

35. EUROPREV. Guía de alimentación saludable. Promover una alimentación saludable mediante el consejo en atención primaria. Barcelona. España. SEMFYC, PAPPS 2005 Disponible en: http://www.papps.es/upload/file/publicaci ones/guia-de-alimentacion-saludable.pdf

36. IMSS. Evaluación y Control Nutricional del Adulto Mayor en Primer Nivel de Atención, México: Secretaria de Salud; Actualización Mayo 2010. ISBN: 978-607-8270-66-8 Disponible en: http://www.imss.gob.mx/sites/all/statics/ guiasclinicas/095GER.pdf 